\title{
Celecoxib ameliorates diabetic neuropathy by decreasing apoptosis and oxidative stress in dorsal root ganglion neurons via the miR-155/COX-2 axis
}

\author{
XIAOLIANG CHENG $^{1 *}$, LING ZHAO ${ }^{1 *}$, TINGYU KE ${ }^{1}$, XI WANG $^{1}$, \\ LIJUN CAO ${ }^{1}$, SHUYAN LIU ${ }^{1}$, JIE HE ${ }^{1}$ and WEI RONG ${ }^{2}$ \\ Departments of ${ }^{1}$ Endocrinology and ${ }^{2}$ Neurology, The Second Affiliated Hospital of \\ Kunming Medical University, Kunming, Yunnan 650101, P.R. China
}

Received February 11, 2020; Accepted March 29, 2021

DOI: $10.3892 / \mathrm{etm} .2021 .10257$

\begin{abstract}
Celecoxib (CXB) is the only clinical cyclooxygenase-2 (COX-2) inhibitor. Oral administration of CXB in experimental diabetic mice effectively relieved the symptoms of diabetic neuropathy (DN); however, the molecular mechanism remains unclear. The present study aimed to investigate the potential molecular mechanisms of CXB in the treatment of DN. An in vitro cellular model of DN was produced by stimulating dorsal root ganglion (DRG) neurons with high glucose. Cell viability and apoptosis were assessed by Cell Counting Kit-8 assays and flow cytometry, respectively. Reactive oxygen species (ROS) kits, ELISA kits and western blotting were used to determine oxidative cellular damage. The expression level of microRNA (miR)-155 was analyzed by reverse transcription-quantitative PCR. The starBase database and dual-luciferase assays were performed to predict and determine the interaction between miR-155 and COX-2. Protein expression of neurotrophic factors, oxidative stress-related proteins and COX-2 were analyzed by western blotting. Incubation with high glucose led to a decrease in DRG neuron cell viability, facilitated apoptosis, downregulated NGF and BDNF expression, increased ROS and MDA generation and decreased SOD activity. Treatment with CXB significantly protected DRG neurons against high glucose-evoked damage. CXB promoted the expression of miR-155 and COX-2 was revealed to be a direct target of miR-155. Inhibition of COX-2 enhanced the protective effect of CXB on DRG neurons and that treatment with an miR-155 inhibitor partially rescued this
\end{abstract}

Correspondence to: Mr. Wei Rong, Department of Neurology, The Second Affiliated Hospital of Kunming Medical University, 374 Dianmian Road, Kunming, Yunnan 650101, P.R. China

E-mail: rong_wei_km@163.com

*Contributed equally

Key words: diabetic neuropathy, celecoxib, oxidative stress, apoptosis, cyclooxygenase-2, microRNA-155 effect. The present study demonstrated the involvement of the miR-155/COX-2 axis in the protective effect of CXB against high glucose-induced DN.

\section{Introduction}

In 2019, an estimated 463 million people worldwide were affected by diabetes mellitus and 5 million people have succumbed to diabetes mellitus (1). The number of individuals with diabetes aged $20-79$ years is predicted to rise to 642 million by $2040(2,3)$. This increase will have adverse social and financial implications and adversely affect health systems. The global healthcare expenditure on people with diabetes was estimated to be 850 billion US dollars in 2017 (2). Diabetes results in end-organ damage and the microvascular complications of nephropathy, retinopathy and neuropathy (4). Diabetic neuropathy (DN), one of the most common complications of diabetes, affects $\geq 50 \%$ of patients with diabetes (5). Its most prominent feature is nerve fiber damage and/or dysfunction, and symptoms of DN usually include numbness, tingling, pain and weakness (6). Although there are numerous pharmacological methods to treat $\mathrm{DN}$, they lack efficacy and cause adverse reactions, such as neuropsychiatric nature, peripheral edema and weight gain (7). In addition to strict glycemic control, researchers have sought potential therapeutic targets and novel pharmacological alternatives (8).

A previous study revealed increased oxidative stress in the pathogenesis of experimental DN. Elevated extra- and intracellular glucose concentrations result in the impairment of antioxidant defense in patients with diabetes and in diabetic animal models $(9,10)$. Hyperglycemia has been proposed to promote reactive oxygen species (ROS) and malondialdehyde (MDA) accumulation and reduce the activity of superoxide dismutase (SOD) (11). An increase in ROS and MDA is directly neurotoxic, promotes neuronal apoptosis (12) and may inhibit mitochondrial respiratory enzymes, resulting in insufficient neural energy production and insufficient neurological function (13). Cyclooxygenase-2 (COX-2) mediates the development of inflammation and is involved in oxidative stress and ROS production (14). Short-term selective chemical COX-2 inhibition in rats and COX-2 gene inactivation in 
mice prevented functional and biochemical peripheral nerve defects caused by diabetes $(13,15)$. Furthermore, nuclear factor erythroid-2-related factor 2 (Nrf2) is involved in antioxidant stress (16). Numerous studies have indicated that persistent hyperglycemia decreases Nrf2 expression (17-19). This downregulation of Nrf2 causes various microvascular changes, ultimately leading to DN (18). Moreover, COX-2-dependent electrophilic oxygen molecules have been demonstrated to act as anti-inflammatory agents by their activation of Nrf2-dependent antioxidant response elements (20). Therefore, selective COX-2 inhibition may be useful for preventing or delaying DN (21).

Celecoxib (CXB) is a nonsteroidal anti-inflammatory drug widely used clinically to treat pain and inflammation $(22,23)$. It has been hypothesized that nonsteroidal anti-inflammatory drugs relieve pain primarily by suppressing the activity of COX proteins (COX-1, COX-2 and COX-3) (24). Among them, COX-2 has been described as a target of CXB (25) and that CXB is the only COX-2 inhibitor currently in clinical use (26). Oral administration of CXB in experimental diabetic mice effectively relieved neuropathic DN pain $(27,28)$; however, the molecular mechanism remains unclear.

MicroRNAs (miRNAs or miRs) are endogenous noncoding single-stranded RNAs consisting of 22 nucleotides (29). The majority of miRNAs are involved in regulating posttranscriptional gene expression (30). It has been hypothesized that miRNAs regulate 1/3 of human genes (31). Furthermore, miRNAs serve a key role in numerous biological processes. Apoptosis, differentiation and metabolism are regulated by base-pairing with targets, causing target mRNA degradation or inhibiting translation (32). The regulation of miR-155 in acute and chronic inflammatory responses has been extensively studied $(33,34)$. Moreover, miR-155 has been demonstrated to serve an important role in peripheral DN (35). miR-155 protects dorsal root ganglion (DRG) neurons by downregulating the inflammatory response (36). However, it remains unclear whether miR-155 affects oxidative stress in DN.

The present study aimed to investigate the molecular mechanism by which CXB relieves DN using a cellular model of DN generated by stimulating DRG neurons with hyperglycemic conditions. Furthermore, the present study also researched the role of $\mathrm{CXB}$ in regulating the expression of miR-155 and COX-2, thereby providing a possible explanation for the effect of $\mathrm{CXB}$ on DN.

\section{Materials and methods}

Cell culture. Mouse DRG neurons were purchased from Qincheng Biotechnology Co., Ltd. (cat. no. MIC-QC-242; Beijing Solarbio Science \& Technology Co., Ltd.). DRG neurons were cultured in DMEM with $10 \% \mathrm{FBS}, 100 \mu \mathrm{g} / \mathrm{ml}$ streptomycin and $100 \mathrm{U} / \mathrm{ml}$ penicillin (all Beijing Solarbio Science \& Technology Co., Ltd.) at $37^{\circ} \mathrm{C}$ with $5 \% \mathrm{CO}_{2}$ in a humid atmosphere. The neurons were cultured for a few passages prior to subsequent experiments.

Establishment of the cell damage model and CXB treatment. To mimic diabetes and DN in vitro, DRG neurons were cultured in complete medium supplemented with 50 mM glucose (cat. no. G8150; Beijing Solarbio Science \&
Technology Co., Ltd.). DRG neurons were maintained under high-glucose conditions at $37^{\circ} \mathrm{C}$ with $5 \% \mathrm{CO}_{2}$ for $48 \mathrm{~h}$ (D) or $72 \mathrm{~h}$ (DN). DRG neurons in the negative control (NC) group were cultured in complete medium containing $25 \mathrm{mM}$ glucose conditions at $37^{\circ} \mathrm{C}$ with $5 \% \mathrm{CO}_{2}$ for $48 \mathrm{~h}$, which is optimal for DRG neuron survival and growth (37).

To determine the effect of CXB (cat. no. IC0230; Beijing Solarbio Science \& Technology Co., Ltd.) on DN, DRG neurons in the DN group were incubated with $\mathrm{CXB}$ at various concentrations $(0,1,5,15,30$ or $50 \mu \mathrm{M})$ for $24 \mathrm{~h}$ prior to subsequent experiments.

Cell transfection. miR-155 inhibitors (5'-ACCCCUAUCACA AUUAGCAUUAA-3'), NC inhibitors (5'-CAGUACUUUUGU GUAGUACAA-3'), miR-155 mimics (5'-UUAAUGCUAAUC GUGAUAGGGGU-3'), mimic NC (5'-UCACAACCUCCU AGAAAGAGUAGA-3') and predesigned vectors expressing siRNAs targeting COX-2 mRNAs (si-COX-2, 5'-AATGTC CGGGTACAATCGCACCCTGTCTC-3') were purchased from Cytiva. Scrambled siRNA (si-control, 5'-AATTCT CCGAACGTGTCACGT-3'; Qiagen $\mathrm{GmbH}$ ) was used as the NC for si-COX-2. A total of $2 \times 10^{5}$ DRG neurons of the DN group were cultured in 24-well plates and transfected using Lipofectamine ${ }^{\mathrm{TM}} 3000$ (cat. no. L3000008; Invitrogen; Thermo Fisher Scientific, Inc.), according to the manufacturer's protocol. miR-155 inhibitors, miR-155 mimics, NC inhibitors and mimic NC were used at a concentration of $100 \mathrm{nM}$ and si-COX-2 and si-controls were used at a concentration of $50 \mathrm{nM}$. Cells were treated with CXB at $48 \mathrm{~h}$ post-transfection, after which cell suspensions were collected for further analysis.

Cell viability. Cell viability was measured using a Cell Counting Kit-8 (CCK-8; cat. no. C0038; Beyotime Institute of Biotechnology) according to the manufacturer's protocol. DRG neurons were cultured into a 96-well microplate $\left(5 \times 10^{3}\right.$ cells/well) and treated with glucose, CXB and/or transfected. A total of $10 \mu \mathrm{l}$ of CCK- 8 reagent was added to the microplates and incubated at $37^{\circ} \mathrm{C}$ for $2 \mathrm{~h}$. Absorbance at $450 \mathrm{~nm}$ (A450) was detected using a microplate reader (Bio-Rad Laboratories, Inc.). Cell growth curves were plotted based on the average A450 value from 3 replicate measurements.

Apoptosis analysis. Apoptosis was determined with an Annexin V-FITC/propidium iodide (PI) Apoptosis Detection kit (cat. no. E606336-0500; Sangon Biotech, Co. Ltd.) according to the manufacturer's protocol. DRG neurons under various treatment conditions were seeded into 6-well plates $\left(5 \times 10^{5}\right.$ cells/well) and reacted with $5 \mu \mathrm{l}$ of Annexin V-FITC and $10 \mu \mathrm{l}$ of PI in the dark at a room temperature for $5 \mathrm{~min}$. Flow cytometric analysis was performed using a flow cytometer (FACSCalibur; BD Biosciences) and FlowJo software version 7.6 (FlowJo, LLC). The results reflect the combination of early and late apoptotic cells.

ROS assay. ROS generation was detected using a ROS assay kit (cat. no. S0033S; Beyotime Institute of Biotechnology) according to the manufacturer's protocol. DRG neurons under various treatment conditions were seeded into 6-well plates (5x10 5 cells/well). Then, $10 \mu \mathrm{M} 2$,7-dichlorodi-hydrofluorescein 
diacetate (DCFH-DA) was added into each well and incubated at $37^{\circ} \mathrm{C}$ for $30 \mathrm{~min}$ in the dark. The fluorescence intensity at 485 and $530 \mathrm{~nm}$ was examined with a flow cytometer (FACSCalibur; BD Biosciences) to evaluate ROS generation.

ELISA. ELISAs were performed with ELISA kits for malondialdehyde (MDA; cat. no. SBJ-M0411; SenBeiJia Biological Technology Co., Ltd.) and superoxide dismutase (SOD; cat. no. ml037856; Mlbio). A total of $1 \times 10^{5}$ cells under various treatment conditions (glucose, CXB and/or transfection) added to 96-well microplates and processed according to the manufacturer's protocol. Conditioned mediums were collected from the wells at $24 \mathrm{~h}$ after processing. Finally, the absorbance at A450 was detected with a microplate reader (Bio-Rad Laboratories, Inc.) and quantities were calculated with standard curves.

Reverse transcription-quantitative PCR (RT-qPCR). A total of $5 \times 10^{6}$ DRG neurons/sample were harvested following treatments or transfections. Total cellular RNA was isolated using TRIzol $^{\text {TM }}$ Reagent (cat. no. 15596018; Invitrogen; ThermoFisher Scientific, Inc.). RNA concentrations were determined using a NanoDrop spectrophotometer (Thermo Fisher Scientific, Inc.). miR-155 expression was examined by TransScript ${ }^{\circledR}$ Green miRNA Two-Step RT-qPCR SuperMix (cat. no. AQ202-01; Beijing Transgen Biotech Co., Ltd.). The specific primers used were as follows: miR-155 forward, 5'-CTGTATCAA AAGGCCAACTGAA-3' and reverse, 5'-GTGTCTATCCTT ATGAATCGCCA-3'; U6 forward, 5'-AACGAGACGACG ACAGAC-3' and reverse, 5'-GCAAATTCGTGAAGCGTT CCATA-3'. PCR amplification was then conducted using a LightCycler 480 instrument (Roche Diagnostics). The thermocycling conditions were as follows: $95^{\circ} \mathrm{C}$ for $10 \mathrm{sec}$ followed by 40 cycles of $95^{\circ} \mathrm{C}$ for $10 \mathrm{sec}$ and $60^{\circ} \mathrm{C}$ for $30 \mathrm{sec}$. U6 was used as internal controls. Relative expression levels were calculated using the $2^{-\triangle \Delta C q}$ method (38).

Western blotting. DRG neurons under various treatment conditions were seeded into 6 -well plates $\left(5 \times 10^{5}\right.$ cells/well). Crude cell lysates were harvested using RIPA lysis buffer (Beijing Solarbio Science \& Technology Co., Ltd.), according to the manufacturer's protocol. The purity of the protein in extracts was examined by the BCA method. Proteins (100 $\mu \mathrm{g} / \mathrm{lane})$ were separated by $10 \%$ SDS-PAGE and transferred to a PVDF membranes. Nonspecific protein binding was prevented with the addition of blocking buffer [5\% milk, $20 \mathrm{mM}$ Tris- $\mathrm{HCl}$ (pH 7.4), $150 \mathrm{mM} \mathrm{NaCl}$ and $0.1 \%$ Tween-20] for $40 \mathrm{~min}$ at a room temperature. The membranes were incubated with specific primary antibodies (1:2,000; Abcam) against nerve growth factor (NGF; cat. no. ab52918), brain-derived neurotrophic factor (BDNF; cat. no. ab226843), COX-2 (cat. no. ab188183), kelch-like ECH-associated protein 1 (Keap1; cat. no. ab227828), nuclear factor erythroid-2-related factor 2 (Nrf2; cat. no. ab137550), heme oxygenase-1 (HO-1; cat. no. ab189491), superoxide dismutase 1 (SOD1; cat. no. ab13498), SOD2 (cat. no. ab137037) or $\beta$-actin (cat. no. ab115777) were incubated in blocking buffer at $4^{\circ} \mathrm{C}$ overnight. The membranes were then incubated with horseradish peroxidase-conjugated goat anti-rabbit immunoglobulin F (1:10,000; cat. no. ab205718; Abcam) for $60 \mathrm{~min}$ in the dark (at room temperature), and developed using an ECL reagent (cat. no. 32209; Thermo Fisher Scientific, Inc.). Membranes were exposed using chemiluminescence apparatus (Bio-Rad Laboratories, Inc.). ImageJ software (version 1.8.0; National Institutes of Health) was used to quantify the protein grayscale.

starBase database analysis. starBase database (http://starbase. sysu.edu.cn) provides a widely-used noncoding RNA interaction from crosslinking-immunoprecipitation and high-throughput sequencing (CLIP-seq) (39). The database was used to predict potential target sequences of miR-155 and COX-2.

Dual-luciferase reporter assay. The direct binding of COX-2 and miR-155 was verified by dual-luciferase reporter assays. Portions of the wild-type (WT) and mutant (MUT) 3'-untranslated regions (UTRs) of COX-2 mRNA containing the predicted miR-155-targeting regions were synthesized and inserted into the pGL3-report luciferase reporter vector (Sigma-Aldrich; Merck KGaA). miR-155 mimics and NC mimics were cotransfected into cells with pGL3-3'-UTR wild-type or mutant plasmid DNA using Lipofectamine ${ }^{\circledR} 3000$ (cat. no. L3000008; Invitrogen; Thermo Fisher Scientific, Inc.), according to the manufacturer's protocol. After $24 \mathrm{~h}$, relative luciferase activity was analyzed using a dual-luciferase reporter gene analysis system (Promega Corporation) and Renilla luciferase reference plasmids were used for standardization.

Statistical analysis. Statistical analysis was performed using SPSS software (version 19.0; IBM Corp.). Unpaired Student's t-test was used to evaluate the differences between two groups. One-way ANOVA with Tukey's Multiple Range post hoc test was used to determine differences between multiple groups. Data are expressed as the mean \pm standard deviation. $\mathrm{P}<0.05$ was considered to indicate a statistically significant difference.

\section{Results}

DRG neurons are injured by high glucose. To detect the effect of glucose on DRG neurons, DRG neurons were treated with glucose for 48 or $72 \mathrm{~h}$. Cell viability was suppressed and apoptosis was induced by $50 \mathrm{mM}$ glucose for $48 \mathrm{~h}$ compared with the NC group and cell survival was further inhibited by $50 \mathrm{mM}$ glucose treatment for $72 \mathrm{~h}(\mathrm{P}<0.05$; Fig. 1A and B). These results indicated that prolonged exposure to a high glucose concentration damaged the DRG neurons. Thus, high-glucose treatment of DRG neurons for 48 or $72 \mathrm{~h}$ mimicked D or DN, respectively, in vitro.

$C X B$ alleviates the inhibitory effect of DN on DRG neuron survival. CXB (various doses, $1-50 \mu \mathrm{M}$ ) was utilized to treat DRG neurons. Cell viability of DRG neurons was examined to evaluate the cytotoxicity of $\mathrm{CXB}$, which indicated that cell viability was unchanged by treatment with $\mathrm{CXB}$ at different concentrations (Fig. 2A). To examine the effect of CXB on DRG neurons, DRG neurons were treated with CXB at various concentrations. CXB increased DRG neuron viability in the DN group to a certain extent $(\mathrm{P}<0.05$; Fig. $2 \mathrm{~B})$. Considering that $\mathrm{DN}$ DRG neurons treated with $30 \mu \mathrm{M}$ CXB exhibited the highest 
A

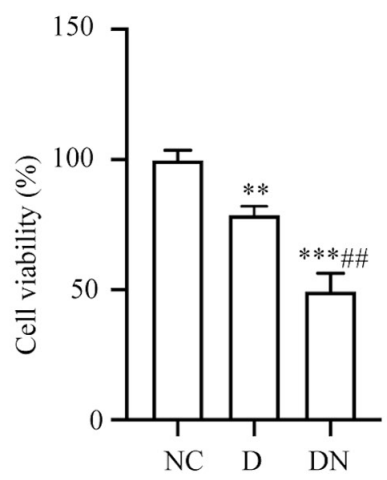

B
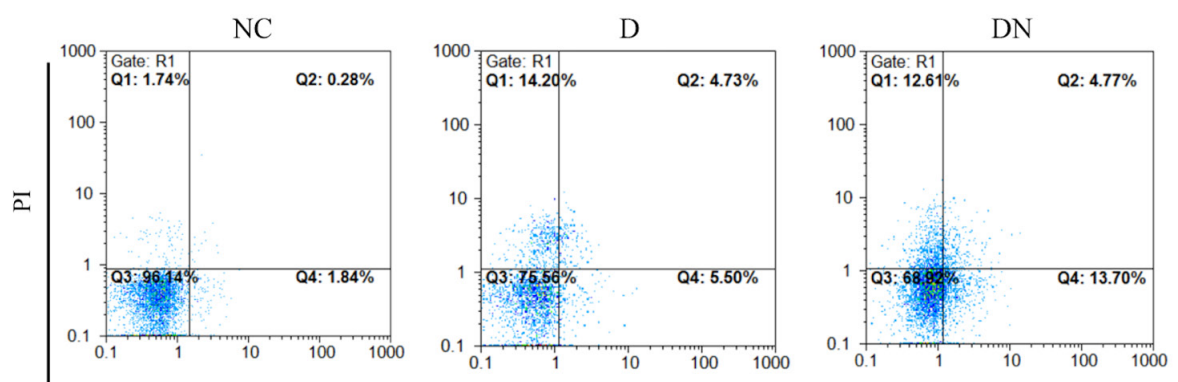

Annxein V-FITC

Figure 1. Dorsal root ganglion neurons are injured by high glucose. Following normal glucose treatment for $48 \mathrm{~h}$ (NC) or high glucose treatment for $48 \mathrm{~h}$ (D) and $72 \mathrm{~h}$ (DN), (A) cell viability was detected using the Cell Counting Kit-8 assay. (B) Cell apoptosis rates were measured using flow cytometry. Data are presented as the mean \pm SD. ${ }^{* *} \mathrm{P}<0.01$ and ${ }^{* * * *} \mathrm{P}<0.001$ vs. NC group, and ${ }^{\# \#} \mathrm{P}<0.01$ vs. D group using One-way ANOVA with Tukey's post hoc test. NC, negative control; D, diabetes; DN, diabetic neuropathy; PI, propidium iodide.

A

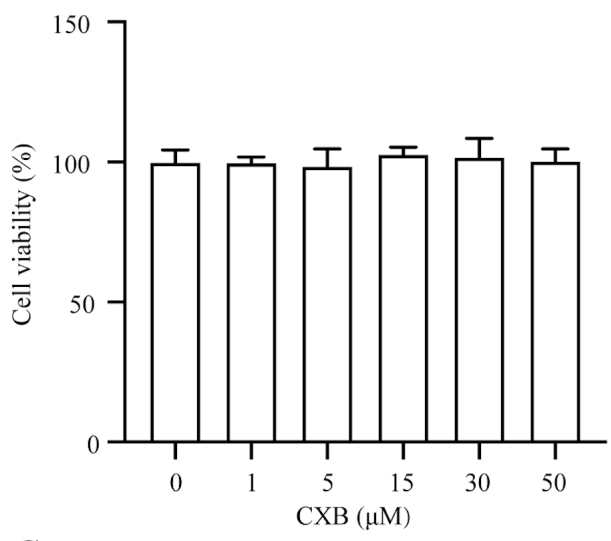

C

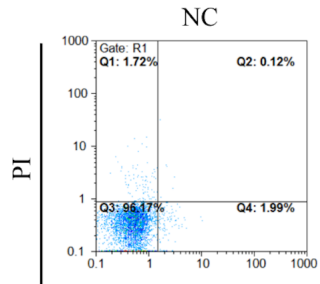

B

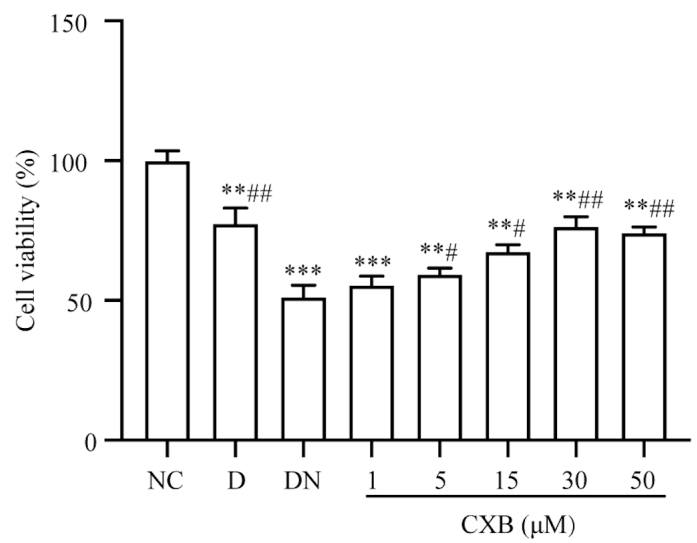

$\mathrm{CXB}(\mu \mathrm{M})$

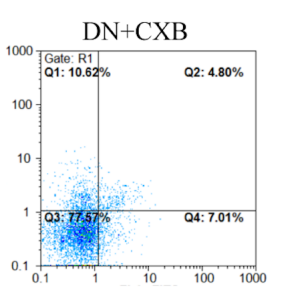

Annxein V-FITC

$\mathrm{D}$
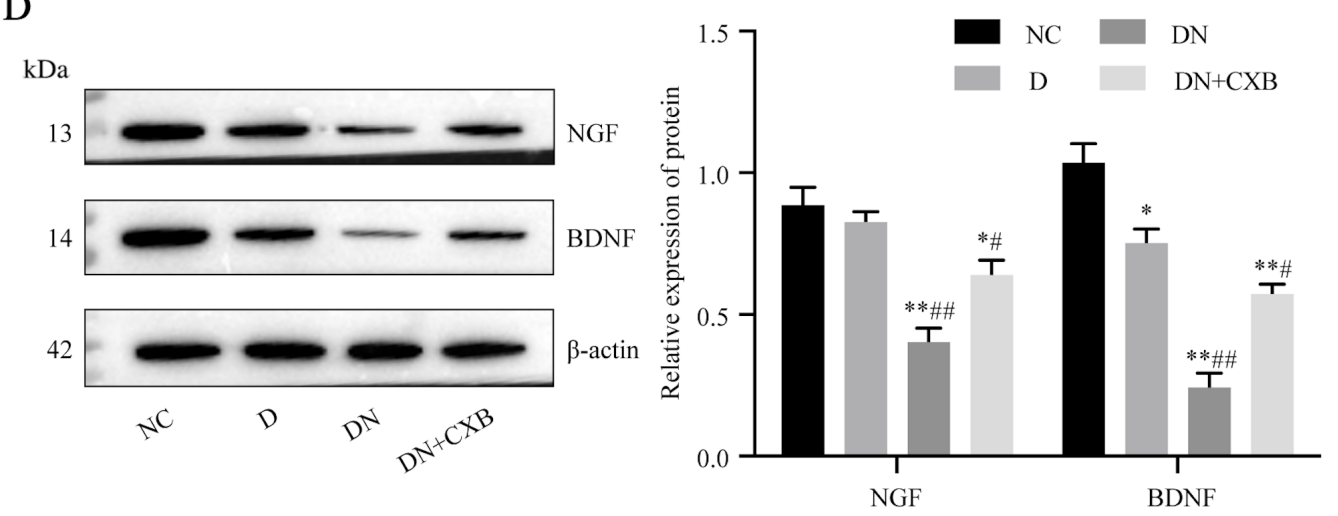

Figure 2. CXB alleviates the inhibitory effect of DN on dorsal root ganglion neuron survival. Following treatment on $\mathrm{NC}$ neurons with $0-50 \mu \mathrm{M} \mathrm{CXB},(\mathrm{A})$ the cytotoxicity of CXB was measured using the CCK-8 assay. Following treatment of DN neurons with $0-50 \mu \mathrm{M}$ CXB, (B) cell viability and (C) cell apoptosis rates were measured using the CCK-8 assay and flow cytometry, respectively. (D) Protein levels of NGF and BDNF were measured using western blotting. Data are presented as the mean \pm SD. In (B), ${ }^{* *} \mathrm{P}<0.01$ and ${ }^{* * *} \mathrm{P}<0.001$ vs. NC group, and ${ }^{\#} \mathrm{P}<0.05$ and ${ }^{\# \#} \mathrm{P}<0.01$ vs. DN group using One-way ANOVA with Tukey's post hoc test. In (D), ${ }^{*} \mathrm{P}<0.05$ and ${ }^{* *} \mathrm{P}<0.01$ vs. NC group, and ${ }^{\#} \mathrm{P}<0.05$ and ${ }^{\# \#} \mathrm{P}<0.01$ vs. D group, using One-way ANOVA with Tukey's post hoc test. CXB, celecoxib; DN, diabetic neuropathy; CCK-8, Cell Counting Kit-8; NGF, nerve growth factor; BDNF, brain-derived neurotrophic factor; PI, propidium iodide. 

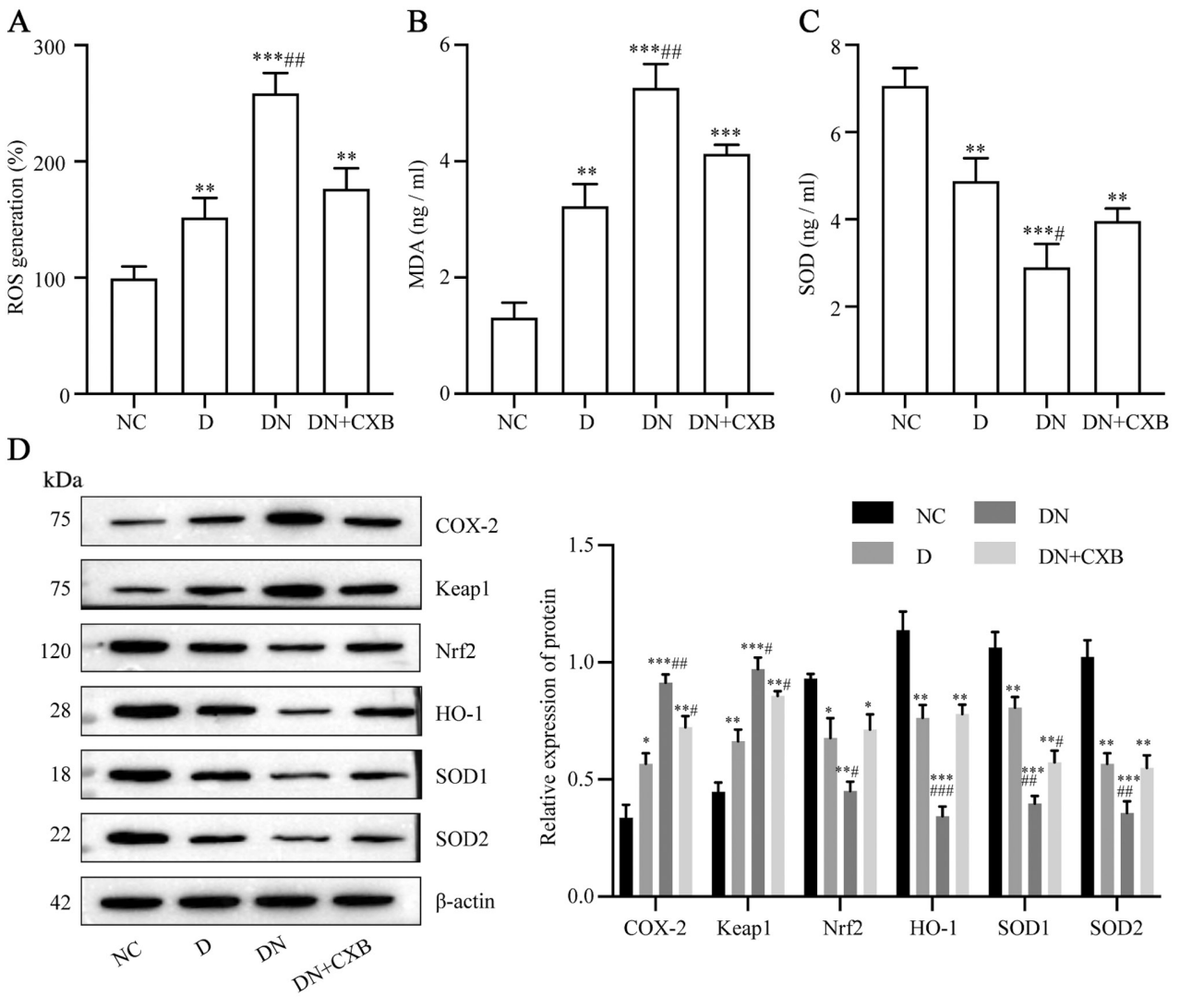

Figure 3. CXB ameliorates DN-induced oxidative stress in dorsal root ganglion neurons. (A) ROS generation was measured using an ROS assay kit. (B) MDA and (C) SOD levels were measured using ELISA kits. (D) The levels of oxidative stress-related proteins were measured using western blotting. Values are presented as the mean $\pm \mathrm{SD} .{ }^{*} \mathrm{P}<0.05,{ }^{* *} \mathrm{P}<0.01$ and ${ }^{* * * *} \mathrm{P}<0.001$ vs. $\mathrm{NC}$ group, and ${ }^{\#} \mathrm{P}<0.05,{ }^{\# \#} \mathrm{P}<0.01$ and ${ }^{\# \# \#} \mathrm{P}<0.001$ vs. $\mathrm{D}$ group, using One-way ANOVA with Tukey's post hoc test. CXB, celecoxib; DN, diabetic neuropathy; ROS, reactive oxygen species; MDA, malondialdehyde; SOD, superoxide dismutase; NC, negative control; D, diabetes; COX-2, cyclooxygenase-2; Keap1, kelch-like ECH-associated protein 1; Nrf2, nuclear factor erythroid-2-related factor 2; HO-1, heme oxygenase-1; SOD1, superoxide dismutase 1; SOD2, superoxide dismutase 2.

viability, $30 \mu \mathrm{M}$ was used as the optimum CXB dose in subsequence experiments. Additionally, apoptosis in DN neurons was attenuated by CXB treatment (Fig. 2C). Furthermore, $\mathrm{DN}$-induced neurotrophic factors NGF and BDNF suppression was attenuated with CXB treatment (Fig. 2D; $<<0.05$ ). These results indicated that $\mathrm{CXB}$ rescued $\mathrm{DN}$-mediated inhibition of DRG neuron survival to a certain extent.

$C X B$ ameliorates $D N$-induced oxidative stress in DRG neurons. DRG neurons were treated with $30 \mu \mathrm{M} \mathrm{CXB}$ and the protective effect of CXB against oxidative stress in neurons was evaluated. The ROS and MDA levels in the DN group were decreased by $\mathrm{CXB}$ treatment $(\mathrm{P}<0.05$; Fig. $3 \mathrm{~A}$ and $\mathrm{B})$. However, the SOD levels were enhanced by CXB treatment $(\mathrm{P}<0.05 ; 3 \mathrm{C})$. Additionally, the levels of oxidative stress-related proteins in each group were assessed. The levels of COX-2 and Keap1 were reduced by CXB treatment, while the levels of Nrf2, HO-1, SOD1 and SOD2 were partially increased by CXB treatment $(\mathrm{P}<0.05$; Fig. 3D). These data indicated that CXB effectively ameliorated oxidative stress in DRG neurons in the $\mathrm{DN}$ group.

$C X B$ prevents $D N$-induced injury in DRG neurons by upregulating miR-155. The regulatory effect of miR-155 on CXB-alleviated DN was investigated. RT-qPCR data demonstrated that miR-155 expression was suppressed in the
DN group (Fig. 4A). Furthermore, miR-155 expression was increased in a dose-dependent manner by CXB treatment $(\mathrm{P}<0.05)$. miR-155 expression in DN-treated DRG neurons was decreased by miR-155 inhibitor transfection ( $\mathrm{P}<0.05$; Fig. 4B). Following this, the importance of miR-155 in the protective function of CXB was determined. Compared to transfection with $\mathrm{NC}$ inhibitor, transfection with miR-155 inhibitor significantly decreased cell viability (Fig. 4C), promoted apoptosis (Fig. 4D), suppressed NGF and BDNF expression (Fig. 4E) and accelerated oxidative damage (Fig. 4F-I; all, $\mathrm{P}<0.05$ ). Moreover, the protective functions of $\mathrm{CXB}$ against DN-induced damage in DRG neurons were partially abrogated by inhibition of miR-155 expression (Fig. 4C-I). These results indicated that miR-155 served an important role in CXB-mediated alleviation of DN.

Prediction of COX-2 as a target of miR-155. The online bioinformatics tool starBase predicted COX-2 as a target of miR-155. The complementary binding sites of COX-2 and miRNA-155 are presented in Fig. 5A. To further confirm the interaction between miR-155 and COX-2, luciferase reporter gene vectors that expressed WT or MUT 3'UTR of the downstream target luciferase gene COX-2 were constructed. The results demonstrated a significant decrease in luciferase activity in the COX-2 $3^{\prime}$ UTR-WT/miR-155 mimic group compared with the COX-2 3'UTR-MUT/miR-155 mimic group 

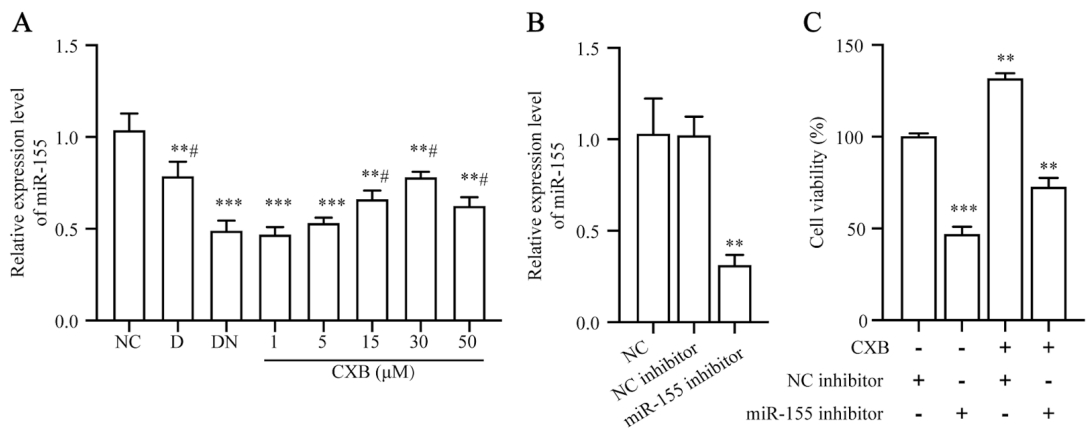

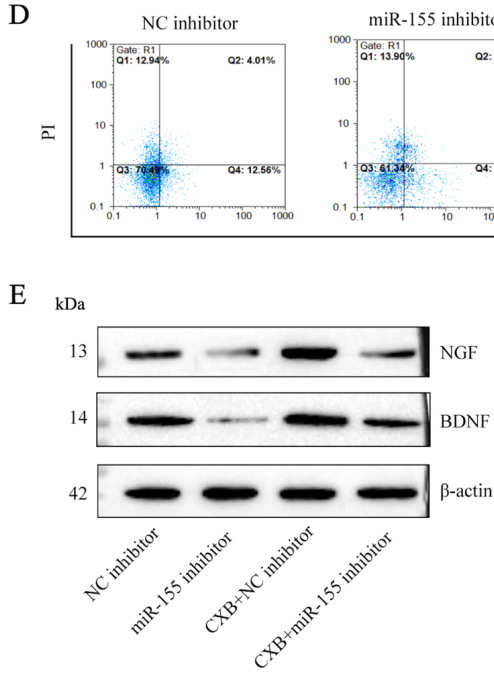

$\mathrm{F}$

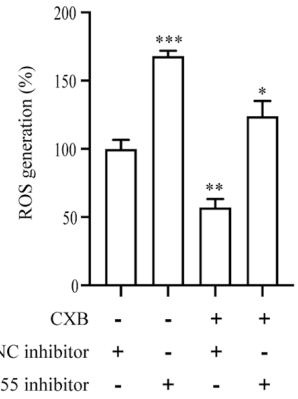

$\mathrm{G}$

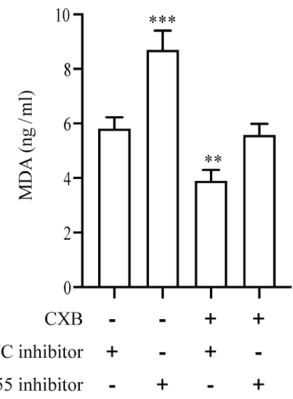

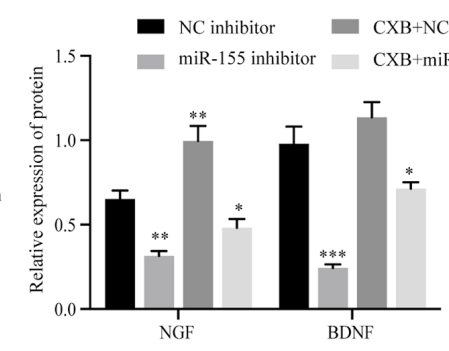

$\mathrm{H}$

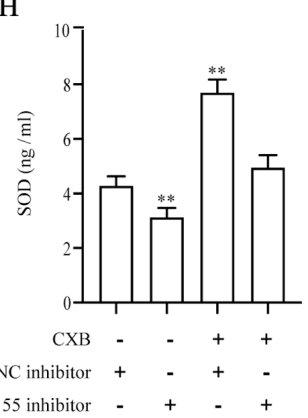

I
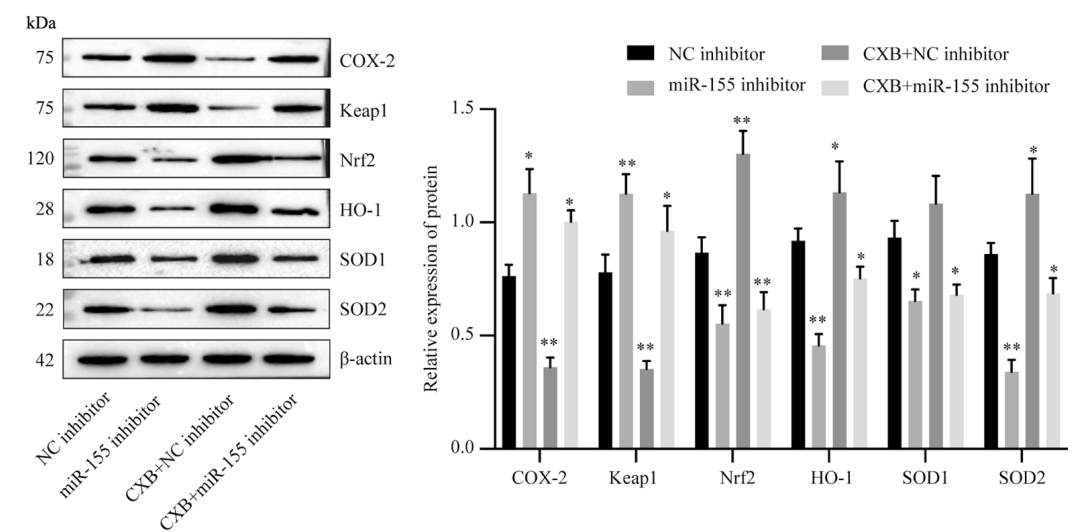

Figure 4. CXB prevents DN-induced injury in dorsal root ganglion neurons by upregulating miR-155. Following treatment of DN neurons with $0-50 \mu \mathrm{M} C X B,(\mathrm{~A})$ the expression of miR-155 was measured using RT-qPCR. (B) Expression of miR-155 in DN neurons following miR-155 inhibitor transfection was measured using RT-qPCR. Following treatment with $30 \mu \mathrm{M}$ CXB and/or miR-155 inhibitor or NC inhibitor transfection, (C) cell viability, (D) the cell apoptosis rate and (E) protein levels of neurotrophic factors were detected using the Cell Counting Kit- 8 assay, flow cytometry and western blotting, respectively. (F) ROS generation was measured using an ROS assay kit, (G) MDA and (H) SOD were measured using ELISA kits and (I) the levels of oxidative stress-related proteins were measured using western blotting. Data are presented as the mean \pm SD. In $(\mathrm{A}),{ }^{* * *} \mathrm{P}<0.01$ and ${ }^{* * *} \mathrm{P}<0.001$ vs. NC group, and ${ }^{\#} \mathrm{P}<0.05$ vs. DN group using One-way ANOVA with Tukey's post hoc test. In Fig. 4B-I, ${ }^{*} \mathrm{P}<0.05,{ }^{* *} \mathrm{P}<0.01$ and ${ }^{* * *} \mathrm{P}<0.001$ vs. NC inhibitor group using One-way ANOVA with Tukey's post hoc test. CXB, celecoxib; DN, diabetic neuropathy; miR, microRNA; RT-qPCR, reverse transcription-quantitative PCR; NC, negative control; ROS, reactive oxygen species; MDA, malondialdehyde; SOD, superoxide dismutase; D, diabetes; NGF, nerve growth factor; BDNF, brain-derived neurotrophic factor; COX-2, cyclooxygenase-2; Keap1, kelch-like ECH-associated protein 1; Nrf2, nuclear factor erythroid-2-related factor 2; HO-1, heme oxygenase-1; SOD1, superoxide dismutase 1; SOD2, superoxide dismutase 2; PI, propidium iodide. 
A

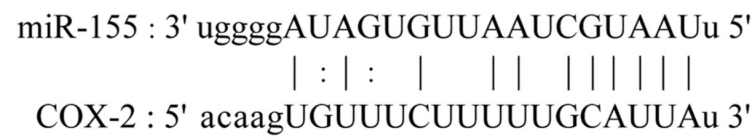

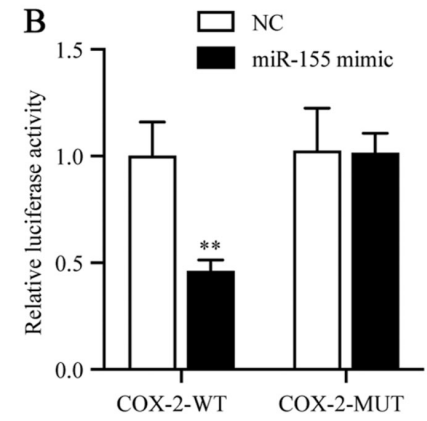

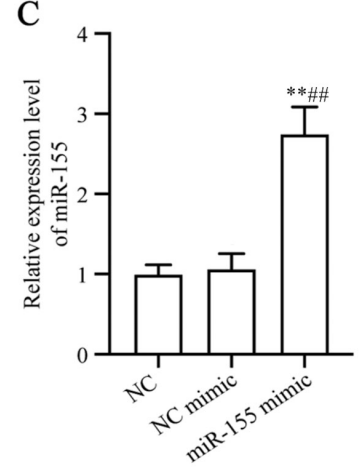

D

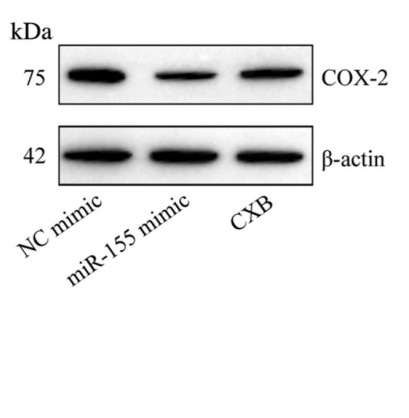

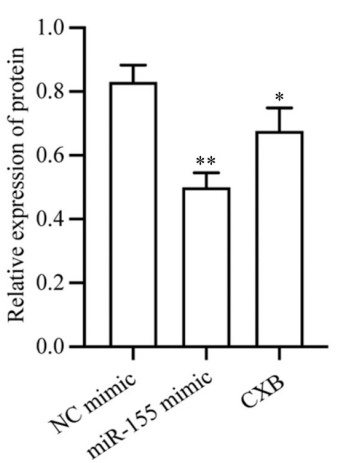

Figure 5. Prediction of COX-2 as a target of miR-155. (A) The starBase database predicted complementary binding sites in COX-2 and miR-155. (B) The targeted relationship between COX-2 and miR-155 was identified using a dual-luciferase reporter gene assay. (C) miR-155 expression in diabetic neuropathy neurons following miR-155 mimic transfection was measured using reverse transcription-quantitative PCR. (D) Protein levels of COX-2 in dorsal root ganglion neurons was assessed using western blotting. Data are presented as the mean \pm SD. In (B), ${ }^{* *} \mathrm{P}<0.01$ compared with the COX-2-MUT group using unpaired student's t-test. In (C), ${ }^{* *} \mathrm{P}<0.01$ vs. NC group and ${ }^{\# \#} \mathrm{P}<0.01$ vs. NC mimic group using One-way ANOVA with Tukey's post hoc test. In $(\mathrm{D}),{ }^{*} \mathrm{P}<0.05$ and ${ }^{* *} \mathrm{P}<0.01$ vs. NC mimic group using One-way ANOVA with Tukey's post hoc test. COX-2, cyclooxygenase-2; miR, microRNA; NC, negative control; WT, wild type; MUT, mutant; CXB, celecoxib.

( $\mathrm{P}<0.01$; Fig. 5B). miR-155 mimic transfection efficiency was detected using RT-qPCR ( $\mathrm{P}<0.05$; Fig. $5 \mathrm{C}$ ). The regulation of COX-2 by miR-155 in DRG neurons was then investigated. The protein expression level of COX-2 was significantly decreased after cells were treated with miR-155 mimics compared with NC mimics $(\mathrm{P}<0.05$; Fig. 5D). These results demonstrated that miR-155 targeted COX-2.

$C X B$ prevents $D N$-induced injury to DRG neurons by regulating the miR-155/COX-2 axis. The mechanism by which miR-155 and COX-2 are involved in CXB-mediated alleviation of DN was investigated. Vectors that expressed si-COX-2 or si-COX-2 plus miR-155 inhibitor were transfected into DRG neurons in the DN group. The protein expression of COX-2 was decreased by si-COX-2 transfection $(\mathrm{P}<0.05$; Fig. 6A). Following this, the association between miR-155 and COX-2 with CXB-mediated alleviation of DN was investigated. Compared to the cell viability in the DN group and CXB treatment group, transfection with si-COX-2 plus $\mathrm{CXB}$ treatment increased cell viability $(\mathrm{P}<0.05$; Fig. 6B), decreased apoptosis (Fig. 6C), upregulated NGF and BDNF expression $(\mathrm{P}<0.05$; Fig. 6D) and reduced oxidative damage $(\mathrm{P}<0.05$; Fig. 6E-H). Furthermore, the protective functions of CXB against DN-induced damage in DRG neurons were partially reduced by si-COX-2 and miR-155 inhibitor transfection plus $\mathrm{CXB}$ treatment $(\mathrm{P}<0.05$; Fig. 6B-H). In summary, these results indicated that $\mathrm{CXB}$ attenuated $\mathrm{DN}$-induced DRG neuron damage and oxidative stress by regulating the miR-155/COX-2 axis.

\section{Discussion}

In the present study, DRG neurons were stimulated with high glucose to mimic DN in vitro and the therapeutic effect of CXB on DN was evaluated. High-glucose conditions led to reduced cell viability and increased apoptosis and ROS generation, indicating that DRG neurons were damaged. Additionally, the function of DRG neurons may have been disturbed, as evidenced by the decreased expression of NGF and BDNF. CXB treatment significantly protected DRG neurons against DN-induced damage. The neuroprotective properties of CXB may be due to the upregulated expression of miR-155, which was inversely associated with expression of COX-2. These in vitro data provided evidence that $\mathrm{CXB}$ attenuated DN-induced damage and oxidative stress in DRG neurons by regulating the miR-155/COX-2 axis.

During the progression of diabetes, long-term hyperglycemic exposure induces neuronal apoptosis, which leads to nerve dysfunction and, ultimately, DN (40). Hyperglycemic conditions increase oxidative stress. Hyperglycemia induces free radicals and produces ROS and MDA, which reduces protein and unsaturated fatty acids synthesis $(11,41,42)$. Furthermore, hyperglycemia impairs the endogenous antioxidant defense system in patients with diabetes (9). SOD is the most potent antioxidant in vivo (43). SOD catalyzes superoxide into oxygen and hydrogen peroxide (44). However, persistent hyperglycemic stimulation decreases SOD activity, which subsequently aggravates damage to DRG neurons by oxidative stress $(45,46)$. Consistently, the results of the present study 
A

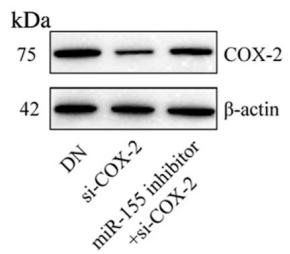

$\mathrm{C}$

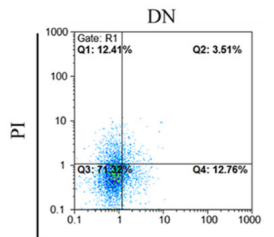

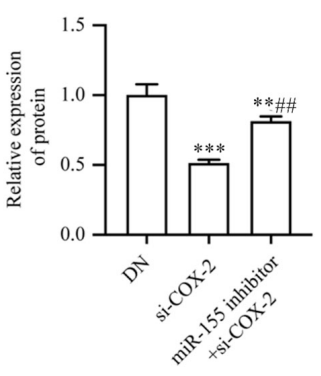

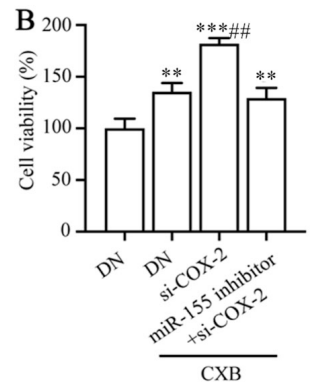

CXB

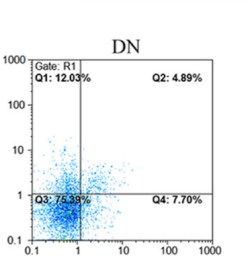

miR-155 inhibito
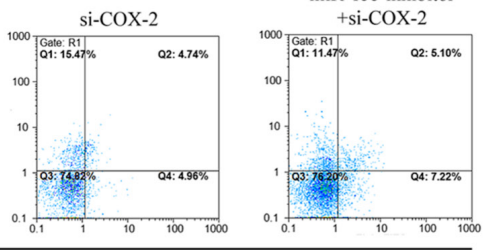

Annexin V-FITC

D $k \mathrm{kDa}$
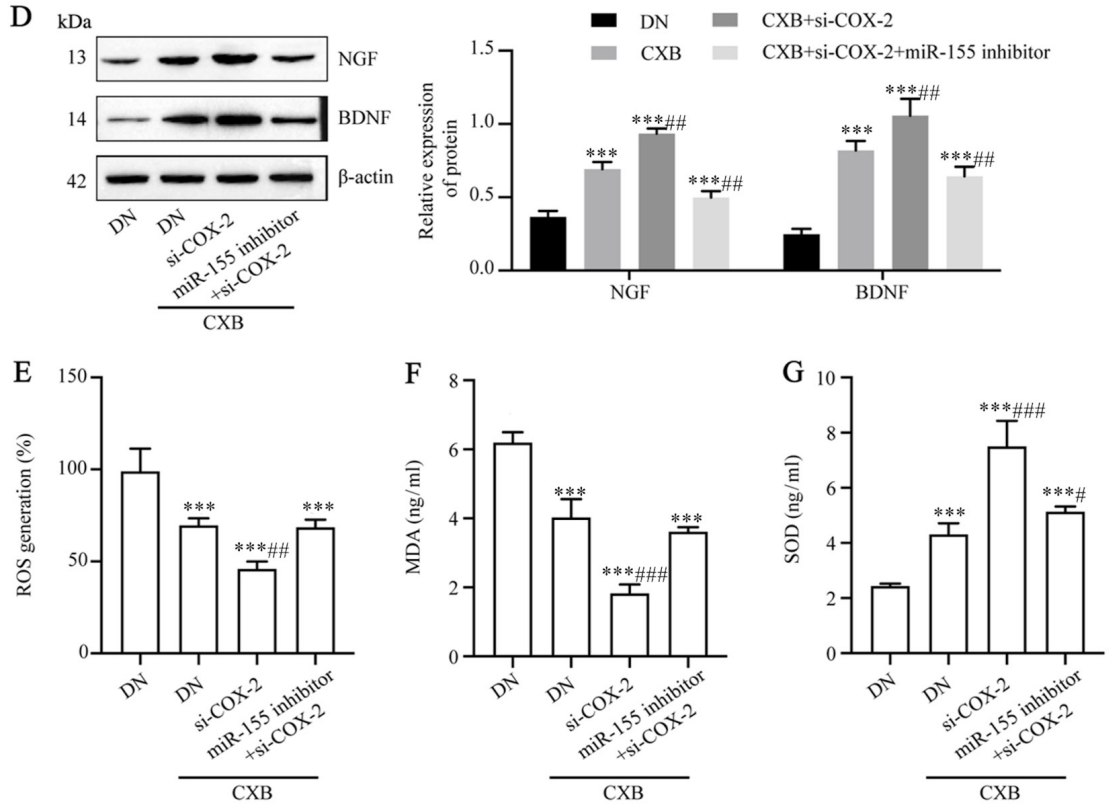

$\mathrm{H} \mathrm{kDa}$
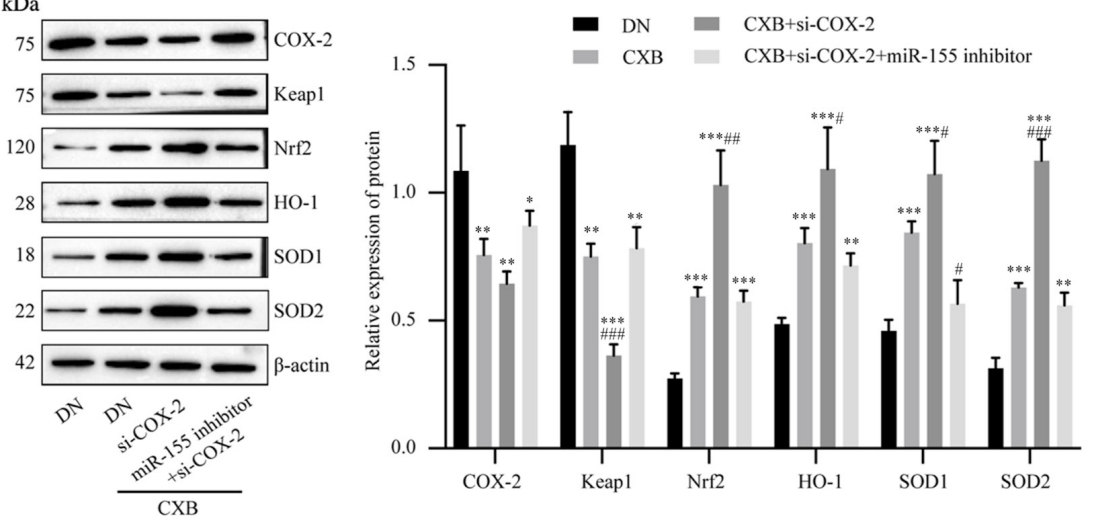

Figure 6. CXB prevents DN-induced injury in dorsal root ganglion neurons by regulating the miR-155/COX-2 axis. (A) The protein levels of COX-2 following transfection with si-COX-2 or si-COX-2 plus miR-155 inhibitor were assessed using western blotting. Following treatment with $30 \mu \mathrm{M}$ CXB and transfection with si-COX-2 or si-COX-2 plus miR-155 inhibitor, (B) cell viability, (C) cell apoptosis rate and (D) protein levels of neurotrophic factors were detected using a Cell Counting Kit-8 assay, flow cytometry and western blotting, respectively. (E) ROS generation was measured using an ROS assay kit, (F) MDA and (G) SOD were measured using ELISA kits and $(\mathrm{H})$ the levels of oxidative stress-related proteins were measured using western blotting. In $(\mathrm{A}),{ }^{* *} \mathrm{P}<0.01$ and ${ }^{* * *} \mathrm{P}<0.001$ vs. DN group, and ${ }^{\# \#} \mathrm{P}<0.01$ vs. si-COX-2 group using One-way ANOVA with Tukey's post hoc test. In $(\mathrm{B}-\mathrm{H}),{ }^{*} \mathrm{P}<0.05,{ }^{* *} \mathrm{P}<0.01$ and ${ }^{* * *} \mathrm{P}<0.001$ vs. DN group, and ${ }^{\#} \mathrm{P}<0.05,{ }^{\# \#} \mathrm{P}<0.01$ and ${ }^{\# \#} \mathrm{P}<0.001$ vs. DN+CXB group using One-way ANOVA with Tukey's post hoc test. CXB, celecoxib; DN, diabetic neuropathy; miR, microRNA; COX-2, cyclooxygenase-2; si-COX, siRNAs targeting COX-2 mRNAs; ROS, reactive oxygen species; MDA, malondialdehyde; SOD, superoxide dismutase; PI, propidium iodide; NGF, nerve growth factor; BDNF, brain-derived neurotrophic factor; Keap1, kelch-like ECH-associated protein 1; Nrf2, nuclear factor erythroid-2-related factor 2; HO-1, heme oxygenase-1; SOD1, superoxide dismutase 1; SOD2, superoxide dismutase 2. 
indicated that the exposure of DRG neurons to high glucose led to an increase in ROS and MDA and a decrease in SOD activity. $\mathrm{CXB}$, the only clinically used COX-2 inhibitor, is involved in regulating apoptosis and ROS production in a variety of cells, such as myocardia cells and neurons (47-49). The present study showed that $\mathrm{CXB}$ has neuroprotective functions in a DN cell model. As revealed by in vitro experiments, $\mathrm{CXB}$ protected DRG neurons from the high glucose-induced loss of viability, apoptosis and ROS production. DRG neurons are the primary neurons of the sensory pathway (50). The unique structure of the stem axons of DRG neurons, which bifurcate into peripheral and central axon branches, may have important implications for their function in health and disease (51). Additionally, NGF and BDNF serve crucial roles in the survival of human DRG neurons (52). CXB was revealed to reduce memory impairment by regulating the BDNF-tropomyosin receptor kinase $\mathrm{B}$ signaling pathway in diabetic rat models (53). The data in the present study demonstrated that $\mathrm{CXB}$ increased BDNF and NGF expression in DRG neurons, thereby increasing DRG neuron survival.

Glucose-mediated oxidative stress and alterations in COX pathway activities have been implicated in the pathogenesis of experimental DN $(15,54)$. Several DN treatments targeting COX-2 have been reported, including rutin in combination with nimesulide (55), Juglans regia L. leaf extract (56) and curcumin (57). As a known inhibitor of COX-2, CXB has been demonstrated to reduce neuropathic pain caused by $\mathrm{DN}$ in rats $(27,58)$. However, to the best of our knowledge, the present study is the first to reveal a possible mechanism for CXB in the treatment of DN. COX-2, also known as prostaglandin $\mathrm{H}$ synthase 2, is a key enzyme that oxidizes arachidonic acid (59) and the products of COX-2 activity participate in various physiological and pathophysiological processes, including pain (60), inflammation, oxidative stress (61) and cancer (62). Groeger et al (63) demonstrated that COX-2 activates Nrf 2 expression by forming a heterodimer with a small Maf protein and binding to the ARE upstream promoter region and that COX-2 regulates the expression of various antioxidant and anti-inflammatory genes, such as Nrf2 and HO-1. The Nrf2/HO-1 signaling pathway is involved in the oxidative stress response (64). In the present study, CXB impacted the levels of Nrf2 and HO-1 by regulating the expression of COX-2. These results indicated that $\mathrm{COX}-2$-mediated oxidative stress may play a role through the $\mathrm{Nrf} 2 / \mathrm{HO}-1$ signaling pathway.

As CXB is a drug for pain and inflammation $(22,23)$, the underlying mechanisms of the function of CXB have been preliminarily investigated. Several studies have indicated that $\mathrm{CXB}$ exerts its functions by regulating miRNA expression patterns. For example, CXB inhibited breast cancer by increasing miR-222 (65) and miRNA-145 was reported to be involved in CXB-mediated inhibition of the epithelial-to-mesenchymal transition in bladder cancer (66) The results of the present study demonstrated that miR-155 is a target of CXB, as its expression was positively regulated by CXB. miR-155 has been widely studied for its reported functions in proliferation (67), apoptosis (68) and lipid metabolism (69). In DN, miR-155 was revealed to protect DRG neurons by downregulating the expression of tumour necrosis factor-associated factor 2, Notch receptor 2 and sortillin 1 (36). The present study demonstrated that miR-155 was involved in regulating oxidative stress by targeting COX-2. Furthermore,
miR-155 may be a key molecular target for the diagnosis and treatment of DN.

This study preliminarily demonstrated the potential therapeutic effect of CXB in DN cell model. In order to better clarify the therapeutic effect of CXB on DN, the protective effect of $\mathrm{CXB}$ on DN in vivo will be further explored, and the underlying molecular mechanisms investigated. In conclusion, the results of the present study may be beneficial for research in related fields for the development of novel treatment strategies for DN.

\section{Acknowledgements}

Not applicable.

\section{Funding}

The present study was supported by the Basic Research Program of Yunnan Province of China [Joint Project of Kunming Medical University; grant no. 2018FE001(-241)] and the Scientific Research Foundation of Yunnan Province Educational Committee (grant no. 2018JS220).

\section{Availability of data and materials}

The datasets used and/or analyzed in the present study are available from the corresponding author on reasonable request.

\section{Authors' contributions}

WR contributed substantially to the study conception and drafting the manuscript. XC and LZ were involved in the study conception and design. XC, LZ, TK and XW performed literature research and the experimental studies. XC, LZ and LC acquired data and edited the manuscript. SL and JH performed data and statistical analyses. WR, XC and LZ were involved in critically revising the manuscript for important intellectual content. All authors read and approved the final manuscript.

\section{Ethics approval and consent to participate}

Not applicable.

\section{Patient consent for publication}

Not applicable.

\section{Competing interests}

The authors declare that they have no competing interests.

\section{References}

1. Saeedi P, Petersohn I, Salpea P, Malanda B, Karuranga S, Unwin N, Colagiuri S, Guariguata L, Motala AA, Ogurtsova K, et al: Global and regional diabetes prevalence estimates for 2019 and projections for 2030 and 2045: Results from the International Diabetes Federation Diabetes Atlas, 9th edition. Diabetes Res Clin Pract 157: 107843, 2019.

2. Ogurtsova K, da Rocha Fernandes JD, Huang Y Linnenkamp U, Guariguata L, Cho NH, Cavan D, Shaw JE and Makaroff LE: IDF diabetes atlas: Global estimates for the prevalence of diabetes for 2015 and 2040. Diabetes Res Clin Pract 128: 40-50, 2017. 
3. Harding JL, Pavkov ME, Magliano DJ, Shaw JE and Gregg EW: Global trends in diabetes complications: A review of current evidence. Diabetologia 62: 3-16, 2019.

4. Javed S, Alam U and Malik RA: Burning through the pain: Treatments for diabetic neuropathy. Diabetes Obes Metab 17: $1115-1125,2015$

5. Callaghan BC, Cheng HT, Stables CL, Smith AL and Feldman EL: Diabetic neuropathy: Clinical manifestations and current treatments. Lancet Neurol 11: 521-534, 2012.

6. Pasnoor M, Dimachkie MM, Kluding P and Barohn RJ: Diabetic neuropathy part 1: Overview and symmetric phenotypes. Neurol Clin 31: 425-445, 2013.

7. Calandre EP, Rico-Villademoros F and Slim M: Alpha delta ligands, gabapentin, pregabalin and mirogabalin: A review of their clinical pharmacology and therapeutic use. Expert Rev Neurother 16: 1263-1277, 2016.

8. Nawroth PP, Bendszus M, Pham M, Jende J, Heiland S, Ries S, Schumann C, Schmelz M, Schuh-Hofer S, Treede RD, et al: The quest for more research on painful diabetic neuropathy. Neuroscience 387: 28-37, 2018

9. Matough FA, Budin SB, Hamid ZA, Alwahaibi N and Mohamed J: The role of oxidative stress and antioxidants in diabetic complications. Sultan Qaboos Univ Med J 12: 5-18, 2012.

10. Piwkowska A, Rogacka D, Audzeyenka I, Jankowski M and Angielski S: High glucose concentration affects the oxidant-antioxidant balance in cultured mouse podocytes. J Cell Biochem 112: 1661-1672, 2011.

11. Piconi L, Quagliaro L and Ceriello A: Oxidative stress in diabetes. Clin Chem Lab Med 41: 1144-1149, 2003.

12. Yang H, Jin X, Kei Lam CW and Yan SK: Oxidative stress and diabetes mellitus. Clin Chem Lab Med 49: 1773-1782, 2011.

13. Pop-Busui R, Marinescu V, Van Huysen C, Li F, Sullivan K, Greene DA, Larkin D and Stevens MJ: Dissection of metabolic, vascular, and nerve conduction interrelationships in experimental diabetic neuropathy by cyclooxygenase inhibition and acetyl-L-carnitine administration. Diabetes 51: 2619-2628, 2002.

14. Smith WL, DeWitt DL and Garavito RM: Cyclooxygenases: Structural, cellular, and molecular biology. Annu Rev Biochem 69: 145-182, 2000.

15. Kellogg AP and Pop-Busui R: Peripheral nerve dysfunction in experimental diabetes is mediated by cyclooxygenase-2 and oxidative stress. Antioxid Redox Signal 7: 1521-1529, 2005.

16. Sies H, Berndt C and Jones DP: Oxidative stress. Annu Rev Biochem 86: 715-748, 2017.

17. Li M, Yu H, Pan H, Zhou X, Ruan Q, Kong D, Chu Z, Li H, Huang J, Huang X, et al: Nrf2 Suppression delays diabetic wound healing through sustained oxidative stress and inflammation. Front Pharmacol 10: 1099, 2019.

18. Kumar A and Mittal R: Nrf2: A potential therapeutic target for diabetic neuropathy. Inflammopharmacology 25: 393-402, 2017.

19. Chen JY, Wang FB, Xu H, Xu LF, Chen D, Liu WH, Mu X and Wen YQ: High glucose promotes prostate cancer cells apoptosis via Nrf2/ARE signaling pathway. Eur Rev Med Pharmacol Sci 23 (Suppl 3): S192-S200, 2019

20. Luo C, Urgard E, Vooder T and Metspalu A: The role of COX-2 and Nrf2/ARE in anti-inflammation and antioxidative stress: Aging and anti-aging. Med Hypotheses 77: 174-178, 2011.

21. Kellogg AP, Cheng HT and Pop-Busui R: Cyclooxygenase-2 pathway as a potential therapeutic target in diabetic peripheral neuropathy. Curr Drug Targets 9: 68-76, 2008

22. Saxena P, Sharma PK and Purohit P: A journey of celecoxib from pain to cancer. Prostaglandins Other Lipid Mediat 147: 106379, 2020 .

23. Tindall E: Celecoxib for the treatment of pain and inflammation: The preclinical and clinical results. J Am Osteopath Assoc 99 (Suppl 11): S13-S17, 1999.

24. Vane JR, Mitchell JA, Appleton I, Tomlinson A, Bishop-Bailey D, Croxtall J and Willoughby DA: Inducible isoforms of cyclooxygenase and nitric-oxide synthase in inflammation. Proc Natl Acad Sci USA 91: 2046-2050, 1994

25. Hawkey CJ: COX-2 inhibitors. Lancet 353: 307-314, 1999.

26. Mi Y, Zhang X, Zhang F, Qi J, Gao H, Huang D, Li L, Zhang H and $\mathrm{Du} \mathrm{X}$ : The role of potassium channel activation in celecoxib-induced analgesic action. PLoS One 8: e54797, 2013.

27. Suarez-Mendez S, Tovilla-Zarate CA, Ortega-Varela LF, Bermudez-Ocaña DY, Blé-Castillo JL, González-Castro TB, Zetina-Esquivel AM, Diaz-Zagoya JC and Esther Juárez-Rojop I: Isobolographic analyses of proglumide-celecoxib interaction in rats with painful diabetic neuropathy. Drug Dev Res 78: 116-123, 2017.
28. Juárez-Rojop IE, Morales-Hernández PE, Tovilla-Zárate CA Bermúdez-Ocaña DY, Torres-Lopez JE, Ble-Castillo JL, Díaz-Zagoya JC and Granados-Soto V: Celecoxib reduces hyperalgesia and tactile allodynia in diabetic rats. Pharmacol Rep 67: 545-552, 2015.

29. Bartel DP: Metazoan microRNAs. Cell 173: 20-51, 2018.

30. Correia de Sousa M, Gjorgjieva M, Dolicka D, Sobolewski C and Foti M: Deciphering miRNAs' Action through miRNA editing. Int J Mol Sci 20: 6249, 2019.

31. Hammond SM: An overview of microRNAs. Adv Drug Deliv Rev 87: 3-14, 2015

32. Huntzinger E and Izaurralde E: Gene silencing by microRNAs: Contributions of translational repression and mRNA decay. Nat Rev Genet 12: 99-110, 2011.

33. Mann M, Mehta A, Zhao JL, Lee K, Marinov GK, Garcia-Flores Y, Lu LF, Rudensky AY and Baltimore D: An NF-кB-microRNA regulatory network tunes macrophage inflammatory responses. Nat Commun 8: 851, 2017.

34. Worm J, Stenvang J, Petri A, Frederiksen KS, Obad S, Elmén J, Hedtjärn M, Straarup EM, Hansen JB and Kauppinen S: Silencing of microRNA-155 in mice during acute inflammatory response leads to derepression of c/ebp Beta and down-regulation of G-CSF. Nucleic Acids Res 37: 5784-5792, 2009.

35. El-Lithy GM, El-Bakly WM, Matboli M, Abd-Alkhalek HA, Masoud SI and Hamza M: Prophylactic L-arginine and ibuprofen delay the development of tactile allodynia and suppress spinal miR-155 in a rat model of diabetic neuropathy. Transl Res 177: 85-97, 2016.

36. Chen J, Liu W, Yi H, Hu X, Peng L and Yang F: MicroRNA-155 mimics ameliorates nerve conduction velocities and suppresses hyperglycemia-induced pro-inflammatory genes in diabetic peripheral neuropathic mice. Am J Transl Res 11: 3905-3918, 2019.

37. Chen T, Li H, Yin Y, Zhang Y, Liu Z and Liu H: Interactions of Notch1 and TLR4 signaling pathways in DRG neurons of in vivo and in vitro models of diabetic neuropathy. Sci Rep 7: 14923 , 2017.

38. Livak KJ and Schmittgen TD: Analysis of relative gene expression data using real-time quantitative PCR and the 2(-Delta Delta C(T)) method. Methods 25: 402-408, 2001

39. Li JH, Liu S, Zhou H, Qu LH and Yang JH: starBase v2.0: Decoding miRNA-ceRNA, miRNA-ncRNA and protein-RNA interaction networks from large-scale CLIP-Seq data. Nucleic Acids Res 42 (Database Issue): D92-D97, 2014.

40. Guo C, Quobatari A, Shangguan Y, Hong S and Wiley JW: Diabetic autonomic neuropathy: Evidence for apoptosis in situ in the rat. Neurogastroenterol Motil 16: 335-345, 2004.

41. Suzuki N, Sawada K, Takahashi I, Matsuda M, Fukui S, Tokuyasu H, Shimizu H, Yokoyama J, Akaike A and Nakaji S: Association between polyunsaturated fatty acid and reactive oxygen species production of neutrophils in the general population. Nutrients 12: 3222, 2020.

42. Gehrmann W, Würdemann W, Plötz T, Jörns A, Lenzen S and Elsner M: Antagonism between saturated and unsaturated fatty acids in ROS mediated lipotoxicity in rat insulin-producing cells. Cell Physiol Biochem 36: 852-865, 2015.

43. Valko M, Rhodes CJ, Moncol J, Izakovic M and Mazur M: Free radicals, metals and antioxidants in oxidative stress-induced cancer. Chem Biol Interact 160: 1-40, 2006.

44. He L, He T, Farrar S, Ji L, Liu T and Ma X: Antioxidants maintain cellular redox homeostasis by elimination of reactive oxygen species. Cell Physiol Biochem 44: 532-553, 2017.

45. Liu D, Zhang H, Gu W and Zhang M: Effects of exposure to high glucose on primary cultured hippocampal neurons: Involvement of intracellular ROS accumulation. Neurol Sci 35: 831-837, 2014

46. Russell JW, Berent-Spillson A, Vincent AM, Freimann CL, Sullivan KA and Feldman EL: Oxidative injury and neuropathy in diabetes and impaired glucose tolerance. Neurobiol Dis 30: 420-429, 2008

47. Zhang C, Wang F, Zhang Y, Kang Y, Wang H, Si M, Su L, Xin X, Xue F, Hao F, et al: Celecoxib prevents pressure overload-induced cardiac hypertrophy and dysfunction by inhibiting inflammation, apoptosis and oxidative stress. J Cell Mol Med 20: 116-127, 2016.

48. Crivelli B, Bari E, Perteghella S, Catenacci L, Sorrenti M, Mocchi M, Faragò S, Tripodo G, Prina-Mello A and Torre ML: Silk fibroin nanoparticles for celecoxib and curcumin delivery: ROS-scavenging and anti-inflammatory activities in an in vitro model of osteoarthritis. Eur J Pharm Biopharm 137: 37-45, 2019. 
49. Huang Y, Liu J, Wang LZ, Zhang WY and Zhu XZ: Neuroprotective effects of cyclooxygenase-2 inhibitor celecoxib against toxicity of LPS-stimulated macrophages toward motor neurons. Acta Pharmacol Sin 26: 952-958, 2005.

50. Griso O and Puccio H: Primary cultures of pure embryonic dorsal root ganglia sensory neurons as a new cellular model for Friedreich's Ataxia. Methods Mol Biol 2056: 241-253, 2020.

51. Nascimento AI, Mar FM and Sousa MM: The intriguing nature of dorsal root ganglion neurons: Linking structure with polarity and function. Prog Neurobiol 168: 86-103, 2018.

52. Kaval Oğuz E: Neuronal survival of DRG neurons after neurite transection in vitro promotes by nerve growth factor and brain derived neurotrophic factor. Cell Mol Biol (Noisy-le-Grand) 64 41-46, 2018.

53. Yang Y and Gao L: Celecoxib alleviates memory deficits by downregulation of COX-2 expression and upregulation of the BDNF-TrkB signaling pathway in a diabetic rat model. J Mol Neurosci 62: 188-198, 2017.

54. Sztanek F, Molnárné Molnár Á and Balogh Z: The role of oxidative stress in the development of diabetic neuropathy. Orv Hetil 157: 1939-1946, 2016 (In Hu)

55. Mittal R, Kumar A, Singh DP, Bishnoi M and Nag TC: Ameliorative potential of rutin in combination with nimesulide in STZ model of diabetic neuropathy: Targeting Nrf2/HO-1/NF-kB and COX signalling pathway. Inflammopharmacology 26: 755-768, 2018.

56. Nasiry D, Khalatbary AR, Ahmadvand H, Talebpour Amiri F and Akbari E: Protective effects of methanolic extract of Juglans regia L. leaf on streptozotocin-induced diabetic peripheral neuropathy in rats. BMC Complement Altern Med 17: 476, 2017.

57. Joshi RP, Negi G, Kumar A, Pawar YB, Munjal B, Bansal AK and Sharma SS: SNEDDS curcumin formulation leads to enhanced protection from pain and functional deficits associated with diabetic neuropathy: An insight into its mechanism for neuroprotection. Nanomedicine 9: 776-785, 2013.

58. Bujalska-Zadrożny M, de Cordé A and Pawlik K: Influence of nitric oxide synthase or cyclooxygenase inhibitors on cannabinoids activity in streptozotocin-induced neuropathy. Pharmacol Rep 67: 209-216, 2015.

59. Smith WL, Garavito RM and DeWitt DL: Prostaglandin endoperoxide $\mathrm{H}$ synthases (cyclooxygenases)-1 and -2. J Biol Chem 271: 33157-33160, 1996.
60. LinJ,Zhang Land Yang H:Perioperative administrationof selective cyclooxygenase- 2 inhibitors for postoperative pain management in patients after total knee arthroplasty. J Arthroplasty 28: 207-213, 2013

61. Uchida K: A lipid-derived endogenous inducer of COX-2: A bridge between inflammation and oxidative stress. Mol Cells 25: 347-351, 2008.

62. Vosooghi M and Amini M: The discovery and development of cyclooxygenase-2 inhibitors as potential anticancer therapies. Expert Opin Drug Discov 9: 255-267, 2014

63. Groeger AL, Cipollina C, Cole MP, Woodcock SR, Bonacci G, Rudolph TK, Rudolph V, Freeman BA and Schopfer FJ: Cyclooxygenase-2 generates anti-inflammatory mediators from omega-3 fatty acids. Nat Chem Biol 6: 433-441, 2010.

64. Loboda A, Damulewicz M, Pyza E, Jozkowicz A and Dulak J: Role of Nrf2/HO-1 system in development, oxidative stress response and diseases: An evolutionarily conserved mechanism. Cell Mol Life Sci 73: 3221-3247, 2016.

65. Wong TY,LiF,Lin SM,Chan FL, Chen S and Leung LK: Celecoxib increases miR-222 while deterring aromatase-expressing breast tumor growth in mice. BMC Cancer 14: 426, 2014

66. Liu X, Wu Y, Zhou Z, Huang M, Deng W, Wang Y, Zhou X, Chen L, Li Y, Zeng T, et al: Celecoxib inhibits the epithelial-to-mesenchymal transition in bladder cancer via the miRNA-145/TGFBR2/Smad3 axis. Int J Mol Med 44: 683-693, 2019.

67. Woeller CF, Roztocil E, Hammond C and Feldon SE: TSHR signaling stimulates proliferation through PI3K/Akt and induction of miR-146a and miR-155 in thyroid eye disease orbital fibroblasts. Invest Ophthalmol Vis Sci 60: 4336-4345, 2019.

68. Xu L, Leng H, Shi X, Ji J, Fu J and Leng H: miR-155 promotes cell proliferation and inhibits apoptosis by PTEN signaling pathway in the psoriasis. Biomed Pharmacother 90: 524-530, 2017.

69. Lin X, Jia J, Du T, Li W, Wang X, Wei J, Lin X, Zeng H, Yao L, Chen X, et al: Overexpression of miR-155 in the liver of transgenic mice alters the expression profiling of hepatic genes associated with lipid metabolism. PLoS One 10: e0118417, 2015. 